A - Research concept and design

B - Collection and/or assembly of data

$\mathrm{C}$ - Data analysis and interpretation

D - Writing the article

E - Critical revision of the article

F - Final approval of article

\section{Impact of Lower Extremity Task-Oriented Training on the Quality Of Life of Children with Cerebral Palsy}

\author{
Umaru M. Badaru*1,A-F D, Omoyemi Olubunmi Ogwumike 2,A-F iD, \\ Ade Fatai Adeniyi ${ }^{2, A-F}$ \\ ${ }^{1}$ Department of Physiotherapy, Bayero University, Kano, Nigeria \\ ${ }^{2}$ Department of Physiotherapy, University of Ibadan, Nigeria
}

*Correspondence: Umaru M. Badaru; Department of Physiotherapy, Bayero University, Kano; email: umbadaru.pth@buk.edu.ng

\title{
Abstract
}

Introduction: Children with Cerebral Palsy (CP) often have poor Quality of Life (QOL). Task-oriented training (TOT) is a neurological rehabilitation technique that may improve their QOL. This study investigated the effect of lower extremity TOT on QOL of children with CP.

Material and methods: Participants were recruited from outpatient Physiotherapy clinics of Aminu Kano Teaching Hospital, Murtala Muhammad Specialist Hospital, and Usman International School Kano. They were randomly assigned into TOT and Conventional Physiotherapy Exercise (Control Group [CG]). The TOT practiced were unloaded and loaded sit to stand, forward step up, high stick stepping, circular movement and stair climbing and descending twice weekly for 12 weeks. QOL was assessed using CP-QOL questionnaire at baseline, 6th and 12th weeks and after 6 weeks of follow up. Data were analysed using repeated measures Anova and independent samples t-test at $\alpha<0.05$.

Results: A total of 46 children were recruited but 39 (TOT 20, CG 19) completed the study. The QOL of children in the two groups was comparable at baseline $[\mathrm{P}>0.05]$. There were significant improvements in QOL within-group in both TOT $(\mathrm{F}[1.63,30.87]=145.877, \mathrm{P}<0.0001)$ and CG $(\mathrm{F}[3,54)=23.841, \mathrm{P}<0.0001]$. There were significant betweengroup differences in QOL at the 6th $(\mathrm{t}=3.98, \mathrm{df}=37, \mathrm{p}<0.001)$ and 12th $(\mathrm{t}=8.116, \mathrm{df}=37, \mathrm{p}<0.001)$ weeks and at 6 weeks follow up $(\mathrm{t}=9.14, \mathrm{df}=37, \mathrm{p}<0.001)$.

Conclusions: Both TOT and Conventional Physiotherapy Exercise have improved the QOL of children with CP. TOT is more effective than conventional Physiotherapy Exercise for the improvement of QoL.

Keywords: quality of life, exercise, cerebral palsy, lower extremity, task-oriented training

\section{Introduction}

Cerebral palsy (CP) is a disorder of movement and posture, causing activity limitation, due to non-progressive disturbances that occur in the developing fetal or infant brain $[1,2]$. Researches have reported that children with CP have poor Quality of Life (QOL) $[3,4]$. It has also been shown that caring for a child with $\mathrm{CP}$ has negative impact on the psychological function [5-7] and QOL of their caregivers [8-10]. Task-Oriented Training (TOT) is a contemporary neurological rehabilitation technique that has the prospects of improving the QOL of children with CP. It is a function-based, goaldirected intervention that requires active involvement 
of the patient in a therapy that is task and context-specific, which focused on the accomplishment of functional activities and participation [11]. Task-Oriented Training requires intensive motor training, variable practice and intermittent feedback [12]. The emphasis is on achievement of a set functional goal and not on the movement of any body part [13]. Patients practiced identifiable, functional tasks and focuses on the effectiveness of motor performance in specific actions [14] rather than on eliciting reflexes or motor patterns in isolation [15] or correction of movement pattern or prevention of compensations [14]. It is also based on the premise that improvement in a particular action requires specific practice of that action [13] or practice of activities that are specific to the intended outcome [16], 'we learn what we practice' [17]. There is therefore similarity between the training tasks and the goal of the intervention [18].

The contemporary neurological rehabilitation approach is compatible with systems model of motor control $[12,15,19]$, motor learning $[16,19,20]$ with inputs from behavioral sciences $[14,17,20]$. The system model is based on the assumption that the CNS is heterarchically organized [15,21], and movement is believed to emerge from the interaction among many systems within the individual, the forces of gravity and inertia each contributing to different aspects of control [15,22]. In the contemporary concept of motor learning, interaction among the individual's level of function and the constraints pose by the task and environmental context, determine movement $[23,24]$. As opined by behavioral sciences, effective learning of a motor skill requires patient to be sufficiently motivated to pay attention and participate actively in the therapy; and the environment context be equally motivating and challenging [17]. Hence patient must learn to actively solve the problems inherent to a functional task [24] and organize movement to match the challenges being posed by the environment through both physical and mental practice [13]. Therefore, treatment should include meaningful task training together with the desired environmental changes needed to promote motor skill acquisition [25]. In order to motivate children, the training should involve practice of interesting functional tasks [26] especially by incorporating functional activities that they perform many times daily [27] which are challenging are as well as meaningful to them [16] for example sit-to-stand, step-up [27] and walking exercise.

Furthermore, to date only one study examined the impact of a TOT intervention on the QOL of children with CP [28]. The group-based TOT produced significant improvement in the QOL of children with CP [28]. Interestingly; it is yet to be known whether any individualized TOT could have impact on QOL of children with CP. Hence this study was designed to evaluate the effect of a 12-week lower extremity TOT on the QOL of children with CP.

\section{Materials and methods}

Participants were recruited from outpatient units of physiotherapy clinics of Murtala Muhammad Specialist Hospital, Aminu Kano Teaching Hospital and Usman International School Kano. The research design was a randomised controlled trial and simple random sampling was used in assigning participants into TOT (Experimental group) and conventional physiotherapy exercise (Control Group [CG]). The study has a trial registration number PACTR201602001333320 and was approved by Aminu Kano Teaching Hospital, Kano state hospital management board and University of Ibadan/University College Hospital Ethics committees. Consent of participation was obtained from the caregivers.

\section{Inclusion and exclusion criteria}

Included in this study are children with $\mathrm{CP}$ who are aged 4-12 years (because the CP-QoL child questionnaire is meant for children aged 4-12 years). Those excluded are children with CP who had debilitating illnesses that could affect their QOL negatively e.g. recurrent illnesses before or during the study and those who are unable to walk independently or with a walking aid.

\section{Intervention}

Participants in both TOT and CG received interventions targeting the trunk and lower limbs for 40 minutes each session twice weekly for 12 weeks with 6 weeks of follow-up. There was 5 minutes each for warm up and cool down sessions for each group.

a. The TOT included unloaded and loaded sit-to-stand exercises, forward step up, high stick stepping, circular movement and stair climbing and descending. In the TOT group, the goal of training is the same for both physiotherapists and parents, exercises were individualized, not intensive (distributed practice) with active participation of the children in the exercises. Exercises were practiced in block (block practice) and context specific, with positive and timely feedback (feedback not being frequent and in form of knowledge of result).

b. The CG received conventional physiotherapy exercise such as passive stretches and strengthening exercises targeting all the muscles of the trunk and lower limbs

c. Children in both groups received similar conventional exercises for the upper limbs 
Please note that part of this study has been published recently, the detailed description of the all the interventions can be found there [29].

\section{Assessment of QOL}

The CP QOL questionnaire for children (CP QoL-Child) parent proxy version was used to assess QOL [30]. The instrument has internal consistency $\alpha=0.74-0.92$, and test retest reliability $r=0.76-0.89$ [31]. CP QoL-Child demonstrated the strongest psychometric properties and clinical utility compared with other QOL scales [32]. It consisted of 65 items and each of the items was scored from 1 (Very unhappy) to 9 (Very happy). Scoring involved 3 steps:

1. Items were transformed to a scale with a range of 0-100 points using the following formula (31): A score of 1 was recorded as 0,2 as 12.5, 3 as 25, 4 as $37.5,5$ as 50,6 as $62.5,7$ as 75,8 as 87.5 and 9 as 100 . The item, 'does your child worry about who will take care of them in the future?' was rated on a 5-point scale. For this item, the following formula was used: A score of 1 was recorded as $0 ; 2$ as 25; 3 as $50 ; 4$ as 75 and 5 as 100 .

2. The algebraic mean of item values was computed for each domain [30]

3. Scores from the 7 domains were summed up and divided by 7 to obtain the overall QoL

score for each child

\section{Statistical analysis}

Repeated measures ANOVA was used to analyse within-group data on QOL because baseline data on QOL was normally distributed in both TOT (KolmogorovSmirnov statistic 0.121, df 19; $\mathrm{p}=0.20$; Shapiro-Wilk statistic 0.978, df 19, $\mathrm{p}=0.92$ ) and CG (KolmogorovSmirnov statistic 0.148, df 19; $\mathrm{p}=0.20$; Shapiro-Wilk

Tab. 1. Characteristics of study participants

\begin{tabular}{lcccc}
\hline Variables & $\begin{array}{c}\text { TOT } \\
(\text { Mean } \pm \text { SD) }\end{array}$ & $95 \%$ CI & $\begin{array}{c}\text { CG } \\
(\text { Mean } \pm \text { SD) }\end{array}$ & $95 \%$ CI \\
\hline Age (years) & $8.65 \pm 3.00$ & $7.24-10.06$ & $7.89 \pm 3.11$ & $6.40-9.39$ \\
Waist-Circumference $(\mathrm{cm})$ & $59.42 \pm 11.04$ & $54.10-64.74$ & $55.47 \pm 8.15$ & $51.55-59.40$ \\
Waist-hip Ratio & $0.89 \pm 0.06$ & $0.86-0.92$ & $0.89 \pm 0.05$ & $0.87-0.92$ \\
BMI $\left(\mathrm{kg} / \mathrm{m}^{2}\right)$ & $16.65 \pm 2.81$ & $15.29-18.00$ & $15.44 \pm 2.06$ & $14.45-16.44$ \\
\hline Variables & TOT (Frequency) & Percent & CG (Frequency) & Percent \\
\hline Level of Education & & & & \\
None & 5 & 25.0 & 4 & 21.1 \\
Nursery & $10^{*}$ & 50.0 & 6 & 31.6 \\
Primary & 3 & 15.0 & 7 & 36.8 \\
Junior secondary & 2 & 10.0 & 2 & 10.5 \\
\hline Total & 20 & 100.0 & 19 & 100.0 \\
\hline Gait type+ & & & & - \\
Assymetric gait & 2 & 10.0 & - & 5.3 \\
Jumping gait & 2 & 10.0 & 1 & 63.2 \\
Hemiplegic gait & 10 & 50.0 & 12 & - \\
Ataxic gait & 1 & 5.0 & - & 10.5 \\
Crouch gait & 3 & 15.0 & 21.1 \\
Normal & 1 & 5.0 & - & - \\
Unclassifiable & 20 & 100.0 & 19 & \\
\hline Total & & & & \\
\hline
\end{tabular}

TOT $=$ task-oriented, $\mathrm{CG}=$ control group. *some of the children remain in nursery school because they did not enroll in time due to their condition. 
statistic 0.957 , df $19, p=0.515)$. Independent samples t-test was used to compare between-group data on QOL measured at different pairs of time interval. Analysis was done using SPSS version 20 at a level of significance of $\mathrm{p}<0.05$.

\section{Results}

\section{Characteristics of study participants}

The mean age of the children was $8.7 \pm 3.0$ years (range 4-12 years) and $7.9 \pm 3.1$ years (range 4-12) years for TOT and CG respectively. Ten $10(50.0 \%)$ and $6(31.6 \%)$ of the children in TOT and CG respectively attended nursery schools. Majority of the children in both groups, TOT $10(50.0 \%)$ and CG $12(63.2 \%)$ had hemiplegic gait type and 1 participant (5.0\%) in the TOT had ataxic gait as presented in Table1.

Furthermore, the mean ages of their caregivers were $37.3 \pm 7.2$ (range 24-50) years and $34.4 \pm 7.2$ (range 25-52) years for TOT and CG respectively. Many of the caregivers 19(48.7\%) earned very low incomes and about $15(38.5 \%)$ had secondary school education (Tab. 2).

\section{Changes in QOL across different time intervals within-group}

There was significant improvement within-group in QoL from baseline to the 6-week follow up in the TOT $(\mathrm{F}[1.63,30.87]=145.877, \mathrm{P}<0.0001)$ as presented in Tables 3. Also, there was significant improvement within-group in the scores for QoL from baseline to the 6-week follow up in the CG $(\mathrm{F}[3,54]=23.841$, $\mathrm{P}<0.0001$ (Tab. 3).

The Repeated Measures ANOVA output shows that assumption of sphericity was violated in the TOT group, with Mauchly's test being significant $(\mathrm{W}=0.167$, $\left.\mathrm{x}^{2}=31.718, \mathrm{df}=5, \varepsilon=0.54,0.59, \mathrm{p}<0.0001\right)$, therefore, Greenhouse-Geisser correction was used since $\varepsilon$ is
$<0.75$. In the CG, sphericity was assumed, Mauchly's test was not significant $\left(\mathrm{W}=0.68, \mathrm{x}^{2}=6.405, \mathrm{df}=5\right.$, $\mathrm{p}=0.270)($ Tab. 4).

\section{Comparison of Scores of QOL Between-Group}

It was observed that the two groups were not significantly different in QoL scores at baseline $(t=1.70, d f=37, P>0.05)$. Significant between-group

Tab. 2. Socio-demographic characteristics of the caregivers of children with $\mathrm{CP}$

\begin{tabular}{lc}
\hline Variables & $\mathrm{n}(\%)$ \\
\hline Gender & $2(5.13)$ \\
Male & $37(94.87)$ \\
Female & \\
\hline Occupation & $5(12.8)$ \\
Unemployed & $34(87.1)$ \\
Employed & \\
\hline Level of education & $5(12.8)$ \\
Informal & $5(12.8)$ \\
Primary & $15(38.5)$ \\
Secondary & $14(35.9)$ \\
Tertiary & \\
\hline Level of income & $19(48.7)$ \\
Very Low (< 18,000) & $10(25.6)$ \\
Low ( $18-49,000)$ & $5(12.8)$ \\
Average (\#50-99,000) & $5(12.8)$ \\
High ( 100,000 and above) & \\
\hline Marital status & $3(7.7)$ \\
Divorced & $36(92.3)$ \\
Married & \\
\hline
\end{tabular}

$\mathrm{n}=$ frequency, $\%=$ percent.

Tab. 3. Within-group changes in scores of QOL across different study period

\begin{tabular}{lccccccc}
\hline \multirow{2}{*}{ Groups } & $\begin{array}{c}\text { Baseline } \\
\text { Mean } \pm \mathrm{SD}\end{array}$ & $\begin{array}{c}6^{\text {th }} \text { week } \\
\text { Mean } \pm \mathrm{SD}\end{array}$ & $\begin{array}{c}12^{\text {th }} \text { week } \\
\text { Mean } \pm \mathrm{SD}\end{array}$ & $\begin{array}{c}\text { Follow-up } \\
\text { Mean } \pm \mathrm{SD}\end{array}$ & \multirow{2}{*}{ Df } & F-ratio & \multirow{2}{*}{ P-value } \\
\hline TOT & $56.52 \pm 7.14^{\mathrm{a}}$ & $66.73 \pm 7.70^{\mathrm{b}}$ & $76.98 \pm 6.27^{\mathrm{x}}$ & $77.23 \pm 5.77^{\mathrm{x}}$ & 1.63 & 145.88 & $0.000^{*}$ \\
& $(\mathrm{n}=23)$ & $(\mathrm{n}=23)$ & $(\mathrm{n}=21)$ & $(\mathrm{n}=20)$ & & & \\
CG & $52.34 \pm 8.23^{\mathrm{a}}$ & $56.94 \pm 7.64^{\mathrm{xy}}$ & $58.22 \pm 8.09^{\mathrm{x}}$ & $56.29 \pm 8.37^{\mathrm{y}}$ & 3 & 23.84 & $0.000^{*}$ \\
& $(\mathrm{n}=23)$ & $(\mathrm{n}=21)$ & $(\mathrm{n}=20)$ & $(\mathrm{n}=19)$ & & & \\
\hline
\end{tabular}

Paired t-test post-hoc analysis indicates that items with different superscript (e.g. $\mathrm{X}^{\mathbf{a}}$ and $\mathrm{X}^{\mathbf{b}}$ ) are significantly different and items with at least one same superscript (e.g. $\mathrm{A}^{\mathrm{xy}}$ and $\mathrm{A}^{\mathrm{y}}$ ) are not significantly different. Bonferroni correction adjusted for family-wise errors due to multiple comparisons. TOT $=$ task-oriented training, $\mathrm{CG}=$ control group. 
Tab. 4. Repeated measures ANOVA source table

\begin{tabular}{|c|c|c|c|c|c|c|}
\hline \multicolumn{7}{|c|}{ Tests of Within-Subjects Effects Task-oriented training Group } \\
\hline Source & & $\begin{array}{c}\text { Type III Sum of } \\
\text { Squares }\end{array}$ & $\mathrm{df}$ & Mean Square & $\mathrm{F}$ & Sig. \\
\hline \multirow{4}{*}{ factor 1} & Sphericity Assumed & 5834.67 & 3 & 1944.89 & 145.87 & .000 \\
\hline & Greenhouse-Geisser & 5834.67 & 1.65 & 3591.48 & 145.87 & .000 \\
\hline & Huynh-Feldt & 5834.67 & 1.75 & 3324.83 & 145.87 & .000 \\
\hline & Lower-bound & 5834.67 & 1.00 & 5834.67 & 145.87 & .000 \\
\hline \multirow{4}{*}{ Error(factor1) } & Sphericity Assumed & 759.94 & 57 & 13.33 & & \\
\hline & Greenhouse-Geisser & 759.94 & 30.86 & 24.62 & & \\
\hline & Huynh-Feldt & 759.94 & 33.34 & 22.79 & & \\
\hline & Lower-bound & 759.94 & 19.00 & 39.99 & & \\
\hline \multicolumn{7}{|c|}{ Tests of Within-Subjects Effects Control Group } \\
\hline \multirow{4}{*}{ factor1 } & Sphericity Assumed & 365.59 & 3 & 121.86 & 23.84 & .000 \\
\hline & Greenhouse-Geisser & 365.59 & 2.51 & 145.36 & 23.84 & .000 \\
\hline & Huynh-Feldt & 365.59 & 2.95 & 123.64 & 23.84 & .000 \\
\hline & Lower-bound & 365.59 & 1.00 & 365.59 & 23.84 & .000 \\
\hline \multirow{4}{*}{ Error(factor1) } & Sphericity Assumed & 276.02 & 54 & 5.11 & & \\
\hline & Greenhouse-Geisser & 276.02 & 45.27 & 6.09 & & \\
\hline & Huynh-Feldt & 276.02 & 53.22 & 5.18 & & \\
\hline & Lower-bound & 276.02 & 18.00 & 15.33 & & \\
\hline
\end{tabular}

differences were observed at the $6^{\text {th }}$ week $(\mathrm{t}=3.98$, df $=37, \mathrm{p}<0.001), 12^{\text {th }}$ week $(\mathrm{t}=8.116, \mathrm{df}=37$, $\mathrm{p}<0.001)$ and at the end of 6 weeks of follow-up $(t=9.14, d f=37, p<0.001)$ (Fig. 1).

\section{Discussion}

This study investigated the effects of a 12-week lower extremity TOT on the QOL of children with CP. There was no significant difference in the baseline scores for QOL of children in the TOT and CG. The QOL of children in the two groups were therefore similar at the beginning of the training program, any change in the QOL at different time points during this study could therefore be attributed substantially to the effects of the two exercise training programs. Another observation in this study was that most of the children in both the TOT and CG experienced moderate QOL at the beginning of the interventions, with overall average QOL score being above fifty percent. The possible implication of this finding is that the QOL of the children in both groups were not severely affected by CP at the beginning of the interventions. This is possible because most of the children have once benefited from physiotherapy services before their enrolment into this study which may have helped to maintain their QOL. In contrast, the QOL of children in another study was found to be severely affected with overall average QOL score below forty percent [33]. This is possibly because most of the children in that study have severe motor disabilities [33] whereas all the children in the present study can walk either independently or with the use of walking aid.

In addition, it was found in this study that QOL of the children with CP has improved significantly following the practice of TOT. In the TOT group, the overall average QOL score has significantly increased to about seventy seven percent at the end of the intervention and at the follow up periods. The implication of this finding is that TOT has enhanced the general wellbeing of the children. Most of the children were happy with the improved ability to play with friends, use their arms and legs, do things they wanted to do and participate in social events and recreational activities. They were happy for having access to medical and allied health services such that they do not have to worry much about having $\mathrm{CP}$, pain or discomfort or frequent hospital visits. The insignificant difference observed in the scores for QOL between the $12^{\text {th }}$ week and at the $6^{\text {th }}$ week of follow-up in the TOT group implies that the wellbeing of the children that was improved after undergoing TOT did not deteriorate when training was stopped for six weeks. In 


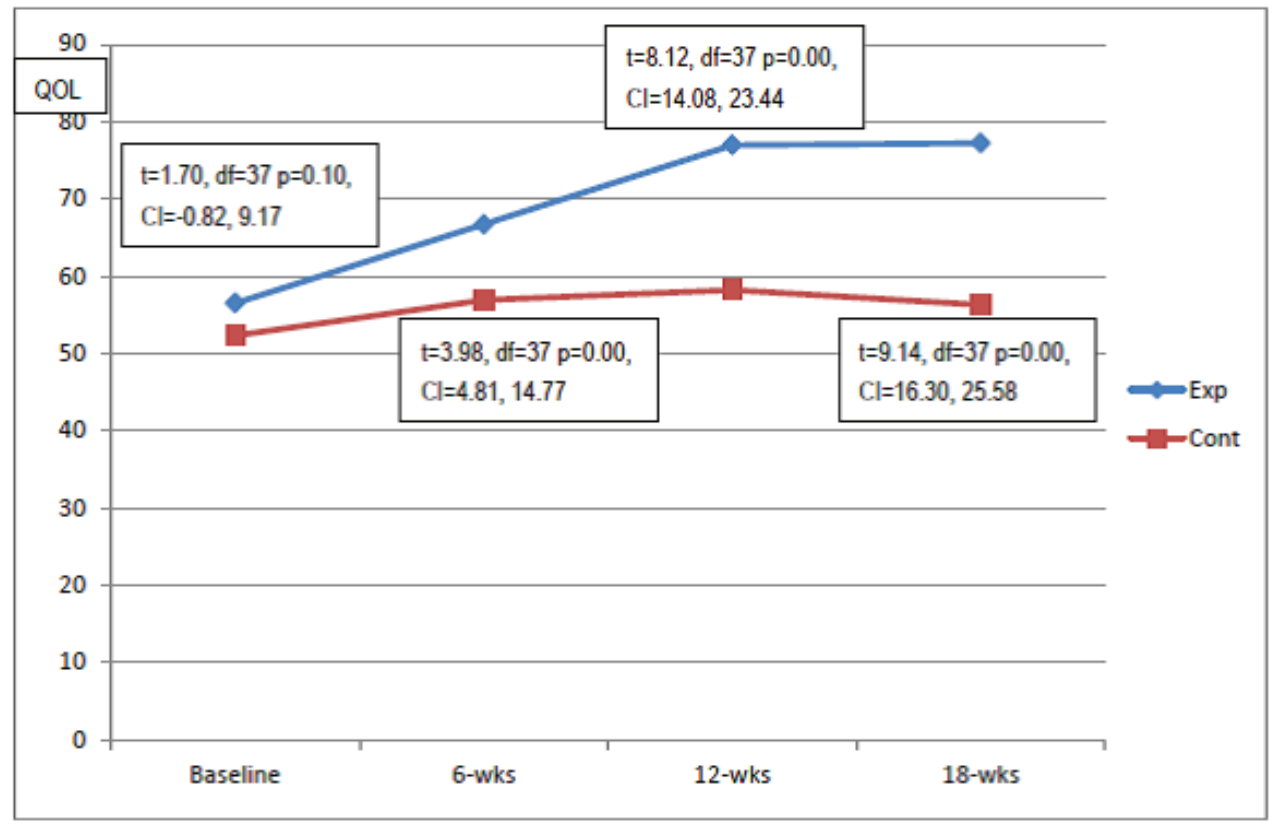

Key: Exp $=$ experimental, Cont= control, wks=weeks, QOL=Quality of Life, $\mathrm{Cl}=95 \%$ confidence interval, $\mathrm{p}=\mathrm{p}$-value

Fig. 1. Comparison of Quality of Life between Experimental and Control groups at Different Study Periods

line with the result of the present study, a study [28] found that 8 months of functional exercise produced significant improvement in the QOL of children and adolescents with CP.

Furthermore, the findings of this study showed that there was significant improvement in the QOL of children in the CG. Similar to the outcome observed in the TOT group, the children who practiced conventional physiotherapy exercise also recorded improved wellbeing in the areas of social interaction and acceptance, physical functioning and participation and decreased pain and disability all leading to improved QOL. The significant reduction in scores for QOL between the $12^{\text {th }}$ week and the $6^{\text {th }}$ week of follow-up implies that the wellbeing of the children that improved with practice of conventional physiotherapy exercises was not maintained when training was stopped. Therefore continuous practice of conventional exercises may be required to maintain the improved QOL of children with CP.

Moreover, though the QOL in the CG was also improved, the overall average QOL score in the post intervention and follow up periods in the CG remain less than sixty percent. This is however; lower when compared with the seventy seven percent in the TOT group. This implies that though children in both groups have experienced improvement in their QOL, children in the TOT group have better improvement in QOL. The fact that children with $\mathrm{CP}$ who underwent TOT achieved significantly better QOL compared with those in the control group at the different time points in the study possibly shows that TOT was more effective when compared with conventional exercise in improving the happiness and wellbeing of children with $\mathrm{CP}$.

In general, physiotherapy interventions that sought to improve the function and strength of the trunk and lower extremities in children with CP thereby improving activity, functional ability, and social participation are likely to improve their QOL $[34,35]$. Furthermore outcomes of researches have shown that QOL in children with $\mathrm{CP}$ could increase with the improvement in physical, social and psychological wellbeing [36], mobility and the ability to perform self-care activities [37]. Also a study has opined that enhancement in the gross motor function of children with CP could lead improvement in the many domains of QOL including social well-being and acceptance, feeling about functioning, participation and physical health [38]. The clinical implication of this study is that Physiotherapists could improve the QOL of children with CP by increasing their motor and functional outcomes through the practice functional training tasks that are meaningful, challenging and interesting to the children especially practice of those tasks that they perform many times daily. It also implies that Physiotherapists could improve the activity, functional mobility, and social participation thereby improving QOL through the practice of lower extremity TOT.

This study has several limitations such as small sample size and short term follow up period that may 
prevent generalization of our findings. The inability to exclude parents who have psychological problems such as depression and those experiencing serious family discord could be a limitation of this study because such parents tend to under report their children's QOL (4). It is recommended that further studies should use also assess QOL from the child's own perspective using the child self-report instruments.

\section{Conclusions}

Both TOT and conventional physiotherapy exercise have improved the QOL of children with CP. However, TOT is more effective than conventional physiotherapy exercise for the improvement of QOL.

\section{Funding}

Tetfund BUK/R/T-EPIC/SBS/N22 for degree awarding research.

\section{Conflicts of interest}

The authors declare no conflict of interest.

\section{References}

1. Rosenbaum P, Paneth N, Leviton A, Goldstein M, Bax M. The definition and classification of cerebral palsy. Dev Med Child Neurol. 2007; 49 Suppl 109: 1-44.

2. Gorter JW, Verschuren O, van Riel L, Ketelaar M. The relationship between spasticity in young children (18 months of age) with cerebral palsy and their gross motor function development. BMC Musculoskel disord. 2009; 10(108): 1-9.

3. Tella BA, Gbiri CA, Osho OA, Ogunrinu AE. Healthrelated quality of life of Nigerian children with cerebral palsy. DCID 2011; 22 (1): 95-104.

4. Badaru UM, Ogwumike OO, Adeniyi AF, Naziru AI. Relationship between caregiver related factors and their proxy report of quality of life of children with cerebral palsy in Kano City, Nigeria. Nig J Med Rehabil. 2019; 20(1): 1-17.

5. Ogwumike OO, Adeniyi AF, Obidiegwu CJ. Psychosocial impact of caring for children with cerebral palsy on the family in a developing country. J Pediatr Neurol. 2012; 10(2): 117-24.

6. Badaru UM, Ogwumike OO, Adeniyi AF, Kaka B. Psychosocial Adversities and Depression in mothers of children with cerebral palsy in Nigeria. J Pediatr Neurol. 2013; 11(1-7): 1304-2580.

7. Olawale OA, Deih AN, Yaadar RK. Psychological impact of cerebral palsy on families: The African perspective. J Neurosci Rural Pract. 2013; 4: 159-63.
8. Hamzat TK, Mordi EL. Impact of caring for children with cerebral palsy on the general health of their caregivers in an African community. Int J Rehabil Res. 2007; 30(3): 191-4.

9. Adegoke BOA, Adenuga OO, Olaleye OA, Akosile CA. Quality of Life of Mothers of Children with Cerebral Palsy and their Age-matched Control. Afr J Neurol Sci. 2014; 33 (1): 71-8.

10. Fatudimu MB, Hamzat TK, Akinyinka OO. Comparative quality of life of Nigerian caregivers of children with cerebral palsy. Int J Ther Rehabil. 2014; 20(3).

11. Geijen M, Ketelaar M, Sakzewski L, Palisano R, Rameckers E. Defining functional therapy in research involving children with cerebral palsy: A Systematic Review. Phys Occup Ther Pediatr. 2020; 40(2): 231-46.

12. Almhdawi KA, Mathiowetz VG, White M, delMas RC. Efficacy of Occupational Therapy Task-oriented Approach in Upper Extremity Post-stroke Rehabilitation. Occup Ther Int. 2016 Oct; 23: 444-56.

13. Carr JH, Shepherd RB. The changing face of neurological rehabilitation. Rev Bras Fisioter. 2006; 10(2): 147-56.

14. Gordon AM. Constraint-induced therapy and bimanual training in children with unilateral cerebral palsy. In: Shepherd RB editor. Cerebral Palsy in Infancy. Edinburg: Churchill Livingstone; 2014. p. 307.

15. Horak FB. Assumptions underlying motor control for neurologic rehabilitation. In: Lister, MJ editor. Contemporary Management of Motor Control Problem. Proceedings of the II step conference, 1991. Alexandria VA: Foundation for Physical Therapy, p. 11-27.

16. Salem Y, Godwin EM. Effects of task-oriented training on mobility function in children with cerebral palsy. NeuroRehabil. 2009; 24: 307 - 13.

17. Carr JH, Shepherd RB. Motor Learning Model for Stroke Rehabilitation. Physiother. 1989; 75: 372-79.

18. Toovey R, Bernie C, Harvey AR, McGinley JL, Spittle AJ. Task-Specific Gross Motor Skills Training for Ambulant School-Aged Children with Cerebral Palsy: A Systematic Review. BMJ Paediatr Open. 2017; 1: e000078. doi:10.1136/bmjpo-2017-000078.

19. Kumar C, Ostwal P. Comparison Between Task-Oriented Training and Proprioceptive Neuromuscular Facilitation Exercises on Lower Extremity Function in Cerebral Palsy - A Randomized Clinical Trial. Novel Physiother. 2016; 6: 291.

20. Rowe VT, Neville M. Task-Oriented Training and Evaluation at Home. OTJR: Occup. Particip. Health 2018; 38(1): 46-55.

21. Mathiowetz V, Haugen JB. Motor Behavior Research: Implications for Therapeutic Approaches to Central Nervous System Dysfunction. Am J Occup Ther. 1994; 48(8): 733-45. 
22. Cano-de-la-Cuerda R, Molero-Sánchez A, CarrataláTejada M, Alguacil-Diego IM, Molina-Rueda F, Miangolarra-Page JC, et al. Theories and control models and motor learning: Clinical applications in neurorehabilitation. Neurología 2015; 30(1): 32-41.

23. Shumway-Cook A, Woollacott MH. Motor Control Theory and Practical Applications. $2^{\text {nd }}$ ed. Baltimore: Lippincott Williams and Wilkins; 2001.

24. Choi Y, Jung H. A Commentary on Task-Oriented Interventions in the Functional Mobility and Postural Control of Children with Cerebral Palsy. Int J Neurorehabil. 2018; 5: 314.

25. Kim Y, Lee B-H. Clinical Usefulness of Child-Centered Task-Oriented Training on Balance Ability in Cerebral Palsy. Phys Ther Sci. 2013; 25: 947-51.

26. Blundell SW, Shepherd RB, Dean CM, Adams RD, Cahill BM. Functional strength training in cerebral palsy: a pilot study of a group circuit training class for children aged 4-8 years. Clin Rehabil. 2003; 17: 48-57.

27. Katz-Leurer M, Rotem H, Keren O, Meyer S. The Effects of a 'Home-Based' Task-Oriented Exercise Programme on Motor and Balance Performance in Children with Spastic Cerebral Palsy and Severe Traumatic Brain Injury. Clin Rehabil. 2009; 23: 714-24.

28. Verschuren O, Ketelaar M, Gorter JW, Helders PJ, Uiterwaal CS, Takken T. Exercise training program in children and adolescents with cerebral palsy: A randomized controlled trial. Arch Pediatr Adolesc Med. 2007 Nov; 161(11): 1075-81.

29. Ogwumike OO, Badaru UM, Adeniyi AF, Effect of task-oriented training on balance and motor function of ambulant children with cerebral palsy. Rehabil (Madr). 2019; 53(4): 276-83.

30. Waters E, Davis E, Boyd R, Reddihough D, Mackinnon A, Graham HK et al. Cerebral Palsy Quality of
Life Questionnaire for Children (CP QOL-Child) Manual 2013. Melbourne: University of Melbourne.

31. Waters E, Davis E, Mackinnon A, Boyd R, Graham HK, Lo SK, et al. Psychometric properties of the quality of life questionnaire for children with CP. Dev Med Child Neurol. 2007; 49: 49-55.

32. Carlon S, Shields N, Yong K, Gilmore R, Sakzewski L, Boyd R. A systematic review of the psychometric properties of quality of life measures for school aged children with cerebral palsy. BMC Pediatr. 2010; 10(8): 1-11.

33. Das S, Aggarwal A, Roy S, Kumar P. Quality of life in Indian children with cerebral palsy using cerebral palsy-quality of life questionnaire. J Pediatr Neurosci. 2017; 12: 251-4.

34. Akkaya KU, Elbasan B. The effects of different physiotherapy interventions on the activities of daily living and the quality of life in children with cerebral palsy. Turk J Physther Rehabil. 2015; 26(3): 1-10.

35. Adar S, Dündar U, Demirdal US, Ulaşlı AM, Toktaş $\mathrm{H}$, Solak O. The effect of aquatic exercise on spasticity, quality of life, and motor function in cerebral palsy. Turk J Phys Med Rehab. 2017; 63(3): 239-48.

36. Mc Manus V, Corcoran P, Perry IJ. Participation in everyday activities and quality of life in pre-teenage children living with cerebral palsy in South West Ireland. BMC Pediatrics 2008; 8(50): 1-10.

37. Chulliyil SC, Diwan SJ, Sheth MS, Vyas NJ. Correlation of functional independence and quality of life in school aged children with cerebral palsy. Int J Contemp Pediatr. 2014; 1(1): 32-36.

38. Gharaborghe SN, Sarhady M, Hosseini SMS, Mortazavi SS. Quality of Life and Gross Motor Function in Children with Cerebral Palsy (aged 4-12). Iranian Rehabil J. 2015; 13(2): 58-62. 